\title{
A Half Century of Artificial Elements
}

Until 1940, Earth knew only the 91 elements occurring in nature. This year marks the 50th anniversary of the synthesis and identification of neptunium and plutonium, the first artificial elements beyond atomic number 92 on the periodic table. In the half century since, researchers have added 15 more transuranic elements, up to the as-yet-unnamed element 109.

For centuries alchemists worked at transmuting one element into another, most notably in attempts to turn lead into gold or silver. Though they never succeeded, such alchemical experiments eventually laid the groundwork for the science of chemistry and also compiled an enormous amount of data on chemical reactions and the properties of elements.

Not until 1937 was a truly artificial element added to the list, when Carlo Perrier and Emilio Segré isolated element 43 in Italy, filling the mysterious gap between Mo and $\mathrm{Ru}$ in the periodic table. They bombarded a molybdenum target with deuterium in a cyclotron; after dissolving the target and adding other elemental tracers, they proved that the bombardment had left an extra proton in some molybdenum nuclei, creating the next element in the sequence. Scientists at first thought that the element did occur in nature, but was extremely rare. Only after they were convinced that it was truly artificial did they give it the name of "technetium."

Technetium is an anomaly, however, and the rest of the periodic table remained filled up to element 92, uranium. In 1934 Enrico Fermi had begun bombarding uranium with neutrons, attempting to form the next element in the periodic table. At first Fermi thought he had been successful, along with other researchers including Otto Hahn, Lise Meitner, and Fritz Strassman, who claimed similar results. However, Ida Noddack wrote a paper in 1934 questioning whether the "new" elements were actually just fission fragments, unknown radioactive isotopes of lighter elements. Though Noddack's paper was not noticed at the time, Hahn and Strassman came to the same conclusions in 1939.

In 1940 Edwin M. McMillan and Philip $\mathrm{H}$. Abelson were conducting fission experiments at the University of Califonia, Berkeley, and discovered beta-particle activity with a half-life of 2.3 days. Further investigation led to the announcement, on June 8, 1940, of their discovery of element 93 , produced by $238 \mathrm{U}$ in a slow-neutron reaction that did not involve fission. This was a rather ironic reversal of Fermi's misleading discovery-McMillan and Abelson had been studying fission and instead created the next element. Because the element uranium had been named for the planet Uranus, McMillan and Abelson named their new element neptunium after the next planet in the solar system, Neptune.

That same year, Glenn T. Seaborg, McMillan, Joseph W. Kennedy, and Arthur C. Wahl, also at Berkeley, bombarded uranium oxide with deuterons in a 60-inch cyclotron and succeeded in producing element 94, 238Pu. Following the planetary scheme, they named the element plutonium after Pluto, the ninth planet, discovered by Clyde Tombaugh only 10 years before. The name was suggested in a secret report written March 21, 1942, but not published until after World War II.

In 1941 Seaborg and Kennedy, working with Emilio Segré (one of the codiscoverers of technetium) and Ernest $O$. Lawrence, synthesized the $239 \mathrm{Pu}$ isotope, formed by the beta-decay of the $239 \mathrm{~Np}$ discovered earlier.

Seaborg's group isolated only 0.05 micrograms of $239 \mathrm{Pu}$, but it was enough to show that slow neutrons caused fission in plutonium even more readily than in $235 \mathrm{U}$, the only other fissionable isotope that had been discovered. Because of the war effort and the secret development of the first atomic bomb, this discovery generated sudden and intense interest in the new element. The team of scientists sent announcements of their discovery to the Physical Review in January, March, and May 1941, but they decided to withhold these reports from publication in the interest of national security.

The following year, Seaborg and Morris L. Perlman discovered that $239 \mathrm{Pu}$ did indeed occur naturally in very small concentrations in Canadian pitchblende. This plutonium is not primordial though, but formed through the absorption of neutrons in $238 \mathrm{U}$. The ratio of uranium to plutonium is about 1011 to $1.239 \mathrm{Pu}$ is also found in monazite ore; the $244 \mathrm{Pu}$ isotope occurs in the rare-earth mineral bastnaesite.

Prolonged irradiation of uranium by slow neutrons finally made it possible to prepare microgram amounts of $239 \mathrm{Pu}$ by 1942, and milligram amounts shortly thereafter. In August 1942 Burris B. Cunningham and Louis $B$. Werner at the Metallurgical Laboratory of the University of
Chicago (now Argonne National Laboratory) produced the first pure chemical compound of plutonium free of carrier material and all other foreign matter. The sample was weighed on a microbalance- -2.77 micrograms. This speck provided the first visible sample of a synthetic element, and it yielded a sample large enough for researchers to investigate the material properties of plutonium.

Plutonium is a silvery-white, extremely reactive metal that takes on a yellow tarnish on exposure to air. The metal is highly electropositive and exists in six allotropes below its melting point of $640 \mathrm{oC}$. The alpha form of plutonium, which exists at room temperature and pressure, has the highest electrical resistivity of any metallic element $(145 \mu \Omega-\mathrm{cm})$. A seventh allotrope occurs when the metal is compressed at pressures greater than $0.6 \mathrm{kbar}$

Of all the phases of plutonium, none has the conventional positive or negative signs for both the coefficient of thermal expansion and the temperature coefficient of resistivity-i.e., if the phase expands on heating, the resistance decreases, which is the opposite of what happens with most materials. Plutonium's peculiar thermal expansion behavior makes pure $\mathrm{Pu}$ metal unacceptable as reactor fuel.

The different allotropes caused great confusion among the Manhattan Project workers trying to develop a plutonium weapon, using limited information from such small samples. Two scientists at Los Alamos, New Mexico, bet $\$ 10$ on whether the density of plutonium metal was 14 or $20 \mathrm{~g} / \mathrm{cm}^{3}$-and they were astonished to find that either answer could be correct, depending on a slight temperature difference. Plutonium's low melting point also surprised researchers, and the need to shape perfect hemispheres of the metalas required for the bomb projectadvanced metallurgy by many years.

While milligram samples of the metal were sufficient to conduct basic experiments to determine the properties of plutonium metal, the Manhattan Project required kilograms of the pure element. The first industrial process for isolating plutonium was developed by Stanley G. Thompson, Seaborg, and other collaborators at the Metallurgical Laboratory in the University of Chicago. Thompson's method, a carrier-precipitation process that used bismuth phosphate and lanthanum fluoride as the carrier, was put into practice at the Hanford Engineering Works 
in Washington state. Modern plutonium separation processes also use solvent extraction and ion exchange techniques.

In addition to its original nuclear weapons uses, $239 \mathrm{Pu}$ is also used as a nuclear fuel and for producing radioactive isotopes for research. $238 \mathrm{Pu}$, which has a half-life of 87.7 years, is used for heart pacemakers and as a heat source for thermoelectric generators on spacecraft and communications satellites. 242Pu and 244Pu have been used extensively in chemical and metallurgical research.

Seaborg and his collaborators continued their string of breakthroughs through the War years, isolating another isotope of uranium, 233U, that could also undergo fission, in 1942. In 1944 Seaborg's team identified element 95, americium (named for America), and element 96, curium (in honor of the Marie and Pierre Curie). The announcement of the latter two discoveries

\section{Seaborg announced the discovery of americium and curium on the "Quiz Kids" radio program.}

came on Armistice Day, November 11, 1945, when Seaborg was a guest on a children's radio show, "Quiz Kids." His work had just been declassified and he planned to give a paper on elements 95 and 96 the following Friday. When one of the children on the show asked him on the air if he had discovered any more elements like plutonium and neptunium, Seaborg broke the news. As he later remarked, "This was the only time in the history of the world that the announcement of the discovery of chemical elements was sponsored by Alka Seltzer."

After World War II, Seaborg and his coworkers discovered elements 97 and 98, berkelium and californium, named for Berkeley, California, where their university was located.

All the additional transuranic elements fell into place on the periodic table, but it soon became apparent that a second set of rare-earth elements existed. This forced a modification of the periodic table to break the rare earths into two series, the lanthanides and actinides, named for the initial elements in each. Niels Bohr had predicted this several years before. As a result of their work with the transuranic elements, Seaborg and McMillan shared the 1951 Nobel Prize in chemistry.

KEVIN J. ANDERSON

\section{Second International Conference on the} New Diamond Science and Technology

\section{September 23-27, 1990}

Washington, DC

\section{Conference Topics:}

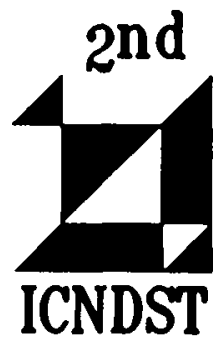

Preparation, characterization, and properties of diamond and related materials by novel low pressure routes

High pressure synthesis, sintering, and crystal growth and characterization

Physics, chemistry, and geosciences of diamond

Applications

Oral and poster sessions will be arranged for each of the conference topics and for subtopics such as vapor growth methods, nucleation and growth phenomena, homoepitaxy, etc.

Call for Papers Deadline: May 1, 1990

Registration:

Full Registration

Student Registration

$\begin{array}{cc}\text { Advance } & \text { On-Site } \\ \$ 225 & \$ 275 \\ \$ 80 & \$ 105\end{array}$

For information contact: 2nd ICNDST Conference Manager, LRW Associates 1218 Balfour Drive, Amold, MD 21012; telephone (301) 647-1591; fax (301) 647-5136.

Sponsored by the Materials Research Society in cooperation with the Electrochemical Society. 